DR. ANDREJA AVBERSEK (Orcid ID : 0000-0002-1352-5127)

PROF. JOSEMIR W. SANDER (Orcid ID : 0000-0001-6041-9661)

DR. PASQUALE STRIANO (Orcid ID : 0000-0002-6065-1476)

-

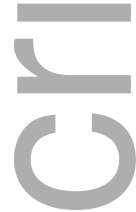

Article type : Full length original research paper

\title{
Comparative effectiveness of antiepileptic drugs in patients with mesial temporal lobe epilepsy with hippocampal sclerosis
}

Ganna Androsova ${ }^{1 a}$, Roland Krause ${ }^{1 a}$, Mojgansadat Borghei ${ }^{2}$, Merel Wassenaar ${ }^{3}$, Pauls Auce 4,5 , Andreja Avbersek ${ }^{6}$, Felicitas Becker7, Bianca Berghuis ${ }^{3}$; Ellen Campbell ${ }^{8}$, Antonietta Coppola ${ }^{9}$, Ben Francis ${ }^{10}$, Stefan Wolking7, Gianpiero L. Cavalleri ${ }^{11}$, John Craig${ }^{8}$, Norman Delanty ${ }^{11,12}$, Bobby P.C. Koeleman ${ }^{13}$, Wolfram S.

Kunz $^{14}$, Holger Lerche ${ }^{7}$, Anthony G. Marson ${ }^{4,5}$, Josemir W. Sander $3,15,16$, Graeme J. Sills ${ }^{4}$, Pasquale Striano ${ }^{9}$, Federico Zara ${ }^{17}$, Sanjay M. Sisodiya ${ }^{6,16}$, Chantal Depondt²,18, the EpiPGX Consortium*

\section{Affiliations}

This is the author manuscript accepted for publication and has undergone full peer review but has not been through the copyediting, typesetting, pagination and proofreading process, which may lead to differences between this version and the Version of Record. Please cite this article as doi: 10.1111/epi.13871

This article is protected by copyright. All rights reserved 
${ }^{1}$ Luxembourg Centre for Systems Biomedicine, University of Luxembourg, Luxembourg

${ }^{2}$ Laboratory of Experimental Neurology, Université Libre de Bruxelles, Brussels, Belgium

${ }^{3}$ Stichting Epilepsie Instellingen Nederland (SEIN), Heemstede, Netherlands

4Department of Molecular and Clinical Pharmacology, Institute of Translational Medicine, University of Liverpool, Liverpool, United Kingdom

${ }^{5}$ The Walton Centre NHS Foundation Trust, Liverpool, United Kingdom

${ }^{6}$ Department of Clinical and Experimental Epilepsy, UCL Institute of Neurology, London, United Kingdom

${ }^{7}$ Hertie Institute for Clinical Brain Research, University of Tübingen, Tübingen, Germany

${ }^{8}$ Belfast Health and Social Care Trust, Belfast, United Kingdom

${ }^{9}$ Pediatric Neurology and Muscular Diseases Unit, Department of Neurosciences, Rehabilitation, Ophthalmology, Genetics, Maternal and Child Health, University of Genoa, Genoa, Italy

${ }^{10}$ Department of Biostatistics, University of Liverpool, Liverpool, United Kingdom

${ }^{11}$ Molecular and Cellular Therapeutics, Royal College of Surgeons in Ireland, Dublin, Ireland

${ }^{12}$ Department of Neurology, Beaumont Hospital, Dublin, Ireland

${ }^{13}$ Department of Genetics, University Medical Center Utrecht, Utrecht, Netherlands

${ }^{14}$ Department of Epileptology, University of Bonn, Bonn, Germany

${ }^{15}$ NIHR University College London Hospitals Biomedical Research Centre, UCL Institute of Neurology, London, United Kingdom 
${ }^{16}$ The Chalfont Centre for Epilepsy, Chalfont St. Peters, United Kingdom

${ }^{17}$ Laboratory of Neurogenetics and Neuroscience, Institute G. Gaslini, Genoa, Italy

${ }^{18}$ Department of Neurology, Hôpital Erasme, Université Libre de Bruxelles, Brussels, Belgium

a Authors contributed equally

*EpiPGX Consortium Contributors are listed in the Appendix

Address correspondence to Chantal Depondt, Department of Neurology, Hôpital Erasme, 808 Route de Lennik, 1070 Brussels, Belgium. Phone: +32/25554622. Fax: +32/25553942. E-mail: Chantal.Depondt@erasme.ulb.ac.be

Running title: AED effectiveness in MTLE-HS

Key words: retention, efficacy, adverse drug reactions, drug response, seizure freedom

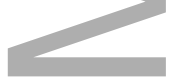

Number of text pages: 13

Number of words: 2443

Number of references: 38

Number of figures: 2

Number of tables: 4

\section{Summary}

Objective: Mesial temporal lobe epilepsy with hippocampal sclerosis (MTLE-HS) is a common epilepsy syndrome often poorly controlled by antiepileptic drug (AED) 
treatment. Comparative AED effectiveness studies in this condition are lacking. We report retention, efficacy and tolerability in a cohort of patients with MTLE-HS.

Methods: Clinical data were collected from a European database of patients with epilepsy. We estimated retention, 12-month seizure freedom and adverse drug reaction (ADR) rates for the 10 most commonly used AEDs in patients with MTLEHS.

Results: Seven hundred sixty-seven patients with a total of 3249 AED trials were included. The highest 12-month retention rates were observed with carbamazepine (85.9\%), valproate $(85 \%)$ and clobazam (79\%). Twelve-month seizure freedom rates varied from $1.2 \%$ for gabapentin and vigabatrin to $11 \%$ for carbamazepine. Response rates were highest for AEDs prescribed as initial treatment and lowest for AEDs used in third or higher instance. ADRs were reported in $47.6 \%$ of patients, with the highest rates observed with oxcarbazepine (35.7\%), topiramate (30.9\%) and pregabalin (27.4\%), and the lowest rates with clobazam (6.5\%), gabapentin (8.9\%) and lamotrigine (16.6\%). The most commonly reported ADRs were lethargy and drowsiness, dizziness, vertigo and ataxia, and blurred vision and diplopia.

Significance: Our results did not demonstrate any clear advantage of newer versus older AEDs. Our results provide useful insights in AED retention, efficacy and ADR rates in patients with MTLE-HS.

Key words: retention, efficacy, adverse drug reactions, drug response, seizure freedom

\section{Introduction}

Mesial temporal lobe epilepsy with hippocampal sclerosis (MTLE-HS) is one of the most common epilepsy syndromes, accounting for up to $65 \%$ of patients with 
temporal lobe epilepsy. ${ }^{1}$ Antiepileptic drug (AED) resistance is common in patients with MTLE-HS and hippocampal sclerosis is identified in about one third of patients with drug-resistant epilepsy undergoing surgical resection. ${ }^{2}$ Several studies have demonstrated that patients with MTLE-HS are significantly less likely to respond to AEDs compared to patients with other focal epilepsy syndromes ${ }^{3}$ and surgery is considered superior to prolonged medical treatment in patients who do not respond to initial treatment. ${ }^{4,5}$ Conversely, it is clear that a subgroup of patients with MTLEHS have seizures that are controlled with AEDs and that the size of this subgroup is systematically underestimated in studies of MTLE-HS, which are mostly conducted in tertiary epilepsy centers. ${ }^{6}$ Moreover, a substantial number of patients with MTLEHS do not undergo surgery for a variety of reasons, including the presence of bilateral lesions, high probability of postoperative neuropsychological deficits or individual choice. ${ }^{7}$ A wide variety of AEDs with differing mechanisms of action and adverse event profiles is now available for the treatment of focal epilepsy. Numerous randomized clinical trials in focal epilepsy have been conducted. These are focused on a particular AED, rather than specific syndromic subgroups such as the population with MTLE-HS. ${ }^{8}$ There is therefore a lack of reliable evidence upon which to base guidelines for AED treatment for patients with MTLE-HS. As a consequence, the medical treatment of these patients largely remains a process of trial and error and any evidence of superiority of one AED over another is lacking. A number of comparative effectiveness studies in patients with focal epilepsy have been reported, but again these have included patients with various types of epilepsy.9,10 To address this knowledge gap, we have evaluated effectiveness by comparing 12-month retention, efficacy (seizure freedom), and tolerability of commonly-used AEDs in a large population of patients with MTLE-HS.

\section{Methods}

Patients with MTLE-HS were identified from a large clinical database developed by the EpiPGX consortium, a European multicentre research project on epilepsy pharmacogenetics (www.epipgx.eu). This database contains phenotypic information 
collected from medical records on over 12000 patients with a confirmed diagnosis of epilepsy, with detailed information on more than 40000 AED trials. Data collection was approved by the Institutional Review Boards of the participating centres and all patients provided written informed consent for use of their clinical data.

We identified 806 patients with a diagnosis of MTLE-HS, recruited from epilepsy centres in Belgium, Germany, Ireland, Italy, the Netherlands and the United Kingdom. The diagnosis of MTLE-HS was confirmed on MRI and/or pathological examination in all individuals. Thirty-four patients with dual pathology were excluded. All AED trials from the time of treatment initiation were considered, with the following exclusions: i) trials started less than one year before the last clinic visit or less than one year before epilepsy surgery, (ii) trials started after epilepsy surgery, (iii) AEDs with average start date before 1985 (phenobarbital, primidone, phenytoin), and (iv) 23 AEDs used in fewer than 70 patients. However, when considering order of AED use, all AEDs and all AED trials were included. The final study population included 767 patients with 3249 trials on 10 different AEDs (see Figure 1).

We recorded duration of treatment, maximum dose, and order of prescription for each of the 3249 AED trials (see Table 2, Supplementary Figure 2 and Table 2). As AED duration data contained some extreme values, we calculated median treatment duration, which is more robust to outliers.

Estimation of 12-month retention rates was done for the 1288 AED trials for which information on duration of treatment was available. For cases with ongoing treatment we considered the date of the last visit if recorded. Twelve-month retention was defined as the proportion of exposed patients remaining on the AED for a period of at least 12 months. We also represented retention as a survival analysis, with median retention estimate as the outcome variable.

Efficacy of AED trials was categorized based on the Consensus proposal of the International League Against Epilepsy ${ }^{11}$ as follows: 1) response (freedom from all 
seizures lasting for $\geq 12$ months, which according to the treating clinician and/or the person undertaking phenotyping can be attributed to the AED, and prior to initiation of another treatment for epilepsy), 2) failure (seizures recurring at $>50 \%$ of the pretreatment seizure frequency after the appropriate AED has been adequately used), 3) unclassified (i.e. neither response nor failure) or 4) unknown. Population percentage response was calculated as the number of responses divided by the total number of known outcomes (response, failure and unclassified).

Lastly, we calculated overall adverse drug reaction (ADR) incidence per AED and the most frequently reported ADRs for each AED. For the purpose of this study, ADRs had to be reported by the treating clinician and/or the person undertaking phenotyping as attributable to the specific AED. All analyses were performed using R software. ${ }^{12}$

To compare the results of median retention, response and ADR rates between AEDs, we compared each AED with the other AEDs in a $2 \times 2$ comparison with $\chi^{2}$ analyses. We calculated p-values by Fisher exact test when $\chi^{2}$ analyses included data with expected values less than 5 . All reported p-values were corrected for multiple comparisons by Bonferroni correction, considering the number of observations as $n$ or $n(n-1) / 2$ in case of pairwise comparisons.

\section{Results}

Demographic and clinical details of the patient cohort are presented in Table 1. Treatment details of each AED are presented in Table 2.

Carbamazepine, used by 615 patients ( $80.2 \%$ ) and valproate, used by 477 patients (62.2\%) were the most commonly used AEDs.

\section{Drug retention}

Carbamazepine with median survival rate of 3.27 years and valproate with median survival rate of 3 years had the highest retention estimates. 
The retention estimate of carbamazepine was statistically higher than those of pregabalin, oxcarbazepine, gabapentin, lamotrigine and topiramate (Bonferroni corrected p-value < 0.01; see Figure 2).

The reason for AED discontinuation was recorded in $54.5 \%$ of treatments. The main reasons were lack of efficacy (26.9\%) and ADRs (12.8\%). See Supplementary Table 3 for details.

\section{Efficacy}

Table 3 shows the treatment outcomes and response (seizure freedom) rates for the 10 AEDs. Twelve-month seizure freedom rates varied between $1.2 \%$ for gabapentin and vigabatrin and $11 \%$ for carbamazepine, while failure rates varied between $41.9 \%$ for pregabalin and $71.8 \%$ for oxcarbazepine. Pairwise comparison of response rates of the 10 AEDs did not show any statistically significant differences.

Seizure freedom rates per AED were too low to allow any correlations between response rate and AED prescription order. Considering all 10 AEDs together, the response rates on AEDs used as the first treatment were higher than those on AEDs used in third or higher instance (13.3\% versus $4.92 \%$, $\mathrm{p}<0.001$ ).

\section{Adverse drug reactions}

ADRs were reported in 365 (47.6\%) patients. The incidence of the 10 most frequent ADRs is presented in Table 4.

ADRs were most commonly reported with oxcarbazepine, topiramate and pregabalin (35.7, 30.9 and $27.4 \%$ of treated patients, respectively). The most commonly reported ADRs were lethargy and drowsiness, dizziness, vertigo and ataxia and blurred vision and diplopia (17.9, 13.9 and 9.5\% of occurrence in all cases, respectively).

ADR rate amongst patients on oxcarbazepine (50 out of 140) was significantly higher than on carbamazepine, clobazam, gabapentin, levetiracetam, lamotrigine and vigabatrin $(\mathrm{p}<0.002$ for all), as well as on valproate $(\mathrm{p}<0.03)$. Similarly, ADR 
rate on topiramate (94 patients out of 304) was significantly higher than on carbamazepine, clobazam, gabapentin, levetiracetam and lamotrigine $(\mathrm{p}<0.003$ for all), as well as on vigabatrin ( $\mathrm{p}<0.02)$. ADR rate on pregabalin $(20$ patients out of 73) was significantly higher than on clobazam $(p<0.001)$ and gabapentin $(p=0.01)$.

\section{Discussion}

Although MTLE-HS represents a well-known and common clinical entity, large scale epidemiological studies are surprisingly scarce. Here we report retention, seizure freedom and ADR rates for the 10 most commonly used AEDs in a large cohort of patients with MTLE-HS. The data provide a unique picture of AED prescription patterns in MTLE-HS in Western Europe over the last decades. Data were collected from multiple sites but stored in a single database, containing detailed data on AED trials, and allowing for uniform data capture and extraction. We applied strict inclusion criteria for case identification and qualifying AED trials. AEDs started before 1985 were excluded as details on these treatments were lacking in a large proportion of cases and because these AEDs (phenobarbital, primidone, phenytoin) are currently rarely used in most Western countries.

The highest retention rates were seen with carbamazepine, valproate and levetiracetam. Reported AED retention rates vary greatly and no previous study has addressed the population with MTLE-HS specifically.9,10,13-16 The relatively high retention rates observed with carbamazepine and valproate might be explained in part by the fact that these AEDs were started earlier on average compared to other AEDs, at a time when relatively fewer AED alternatives were available, which may have restricted clinicians' options for switching AEDs. Conversely, carbamazepine and valproate were more often the first AED used, resulting in higher response rates and fewer drug interactions and ADRs. Retention rates represent a combined reflection of efficacy and tolerability. Our results indeed suggest that AEDs with the highest retention rates (carbamazepine, valproate and levetiracetam) tend to have the highest efficacy rates, while those with the lowest retention rates (pregabalin, oxcarbazepine, topiramate) have the highest ADR rates. 
Twelve-month seizure freedom rates per AED ranged from 1.2 to $11 \%$, providing support to the concept of the refractoriness of MTLE-HS. Previous studies reporting seizure freedom rates in patients with MTLE-HS mostly considered seizure freedom at last follow-up, with widely varying results. ${ }^{17,18}$ A study of 253 patients with MTLE-HS recruited from a tertiary referral centre reported $9 \%$ seizure freedom at one year follow-up. ${ }^{19}$ A study on 68 patients with newly diagnosed MTLE-HS reported seizure-free periods of at least a year in 53\%.7 In a study of 110 patients with MTLE-HS, 31\% remained seizure-free for at least two years. ${ }^{20} \mathrm{~A}$ similar though smaller study reported $29 \%$ of 41 patients with MTLE-HS as being seizure-free or having only focal aware seizures. ${ }^{21}$ These two studies were conducted in nonsurgical cases only. In contrast, our cases were mostly patients with longstanding disease recruited mainly from tertiary referral centres. It has been suggested that seizures tend to become more refractory over time. ${ }^{3,22}$ Our figures may represent an underestimation of true response rates though, as seizure-free periods may have been missed, especially those occurring early in the disease course. Seizure freedom rates were highest with carbamazepine, levetiracetam and oxcarbazepine, although the differences were not statistically significant. No previous studies reported comparative response to individual AEDs in patients with MTLE-HS specifically. In one report the majority of 34 seizure-free patients were treated either with carbamazepine monotherapy or a combination of carbamazepine and levetiracetam, which were also the AEDs with the highest efficacy rates in our study. ${ }^{20}$ In an attempt to differentiate AED response from other causes of seizure freedom, we specifically required seizure freedom to occur before initiation of another treatment and to be attributable to the AED in question, as judged by the clinician or person undertaking phenotyping. We recognize that this method involves a degree of subjective interpretation, the extent of which cannot be measured. Despite these strict criteria, confounding from polytherapy cannot be excluded. Also, in our study as in others, differentiation between natural seizure fluctuation and true AED response is difficult. Prolonged periods of seizure freedom are observed in a substantial proportion of patients with epilepsy followed over long time periods, ${ }^{23-}$ ${ }^{25}$ even in those with chronic, refractory epilepsy. ${ }^{26}$ In a retrospective study, $30 \%$ of 
122 patients with MTLE-HS had a "relapsing-remitting" seizure pattern. ${ }^{27}$ Our strict criteria may have contributed to the relatively low rates of seizure freedom observed in our population. Individual seizure freedom rates per AED were too low to look at an influence of order of AED use. Considering all 10 AEDs together, we noted higher response rates for AEDs used as initial treatment and lowest values for AEDs used in third or higher instance. Our data seem to confirm previous reports of decreasing rates of response with subsequent AED trials, a well-known finding also observed in the general epilepsy population. ${ }^{28,29}$

ADRs were reported in about half of patients. Prevalence rates of ADRs are known to be dependent on the method of assessment. ${ }^{30}$ Published rates of ADR prevalence based on unstructured interviews or spontaneous reporting in patients with epilepsy vary between 10 and $40 \%{ }^{31}$ The higher rate of ADRs in the present study might be explained by the fact that most patients were on polytherapy and therefore exposed to a higher AED load, although this relationship has not been identified in other studies. ${ }^{32,33}$ ADR rates per AED varied between 6.5\% and 35.7\%, with the lowest rates reported with clobazam, gabapentin and lamotrigine, and the highest with oxcarbazepine, topiramate and pregabalin. Our results are comparable with previous studies reporting ADR rates on individual AEDs, although most of these concerned patients on monotherapy. ${ }^{9,10,34}$ The most commonly reported ADRs were lethargy and drowsiness, dizziness/vertigo/ataxia and blurred vision/diplopia. We acknowledge that the prevalence figures of specific ADRs are likely subject to some degree of reporting bias.

Our results did not show any clear advantage of newer versus older AEDs. Our study was largely based on retrospective data collected from medical records, with inherent weaknesses and biases. In particular, considerable proportions of data were missing for some of the collected items. While some of these data were genuinely missing, this is due in part also to the strict definitions we applied, for instance for classifying AED efficacy. Our patients were mostly recruited from tertiary referral centres, likely resulting in a bias towards more severely affected patients. Our results thus may not be applicable to the overall population with 
MTLE-HS. Also, our data are observational and therefore should not be interpreted as evidence of superiority of one AED over the other, an issue which can only be addressed in a randomized clinical trial in this specific population. It seems unlikely however that randomized clinical trials in specific patient populations will be carried out in the foreseeable future. Our study is the first to provide an indication of the effectiveness of medical treatments in a sizeable cohort of patients with a well-defined focal epilepsy syndrome and the results may inform further prospective studies. It is clear that such studies can only be realized through large, multicentric collaborations as the one illustrated here. Along the lines of recent reports describing the success of personalized treatments in specific epilepsy syndromes, mostly of monogenic origin, ${ }^{35-38}$ these studies may help direct treatment in well-characterized subgroups of patients with specific epilepsy syndromes, ultimately leading to more efficacious and less harmful treatments.

\section{Key Points}

- Comparative AED effectiveness studies in specific focal epilepsy syndromes are lacking

- We conducted a large retrospective database study on effectiveness of 10 AEDs in patients with MTLE-HS

- The highest 12 -month retention rates were observed with carbamazepine

- Twelve-month seizure freedom rates on individual AEDs varied from $1.2 \%$ to $11 \%$

- ADRs were reported in nearly half of patients, with the highest rates with oxcarbazepine and the lowest with clobazam 


\section{Appendix}

\section{EpiPGX Consortium Contributors}

Martin J. Brodie; Krishna Chinthapalli; Gerrit-Jan de Haan; Colin Doherty; Lárus J. Gudmundsson; Sinead Heavin; Andres Ingason; Michael Johnson; Clare Kennedy; Martin Krenn; Mark McCormack; Terence J. O’Brien; Massimo Pandolfo; Ekaterina Pataraia; Slave Petrovski; Sarah Rau; Narek Sargsyan; Lisa Slattery; Kári Stefánsson; William Stern; Anna Tostevin; Joseph Willis; Fritz Zimprich.

\section{Acknowledgments}

We wish to thank Vicenzo Belcastro, Amedeo Bianchi, Francesca Bisulli, Giuseppe Capovilla, Giovanni Crichiutti, Simona Donatello, Antonio Gambardella, Anna Teresa Giallonardo, Christian Hengsbach, Angela La Neve, Benjamin Legros, Carla Marini, Roberto Michelucci, Susanne Schubert-Bast, Bernhard Steinhoff, Wim Van Paesschen, Aglaia Vignoli, and Yvonne Weber for assisting with patient recruitment. We wish to acknowledge all contributing patients and clinicians.

This work was supported by a grant from the European Commission $\left(7^{\text {th }}\right.$ Framework Programme Grant 279062, EpiPGX). Ganna Androsova has received funding from the framework of the EU-funded FP7 research program BioCog (Biomarker Development for Postoperative Cognitive Impairment in the Elderly): www.biocog.eu. This work was partly undertaken at UCLH/UCL Comprehensive Bio-Medical Research Centre, which received a proportion of funding from the Department of Health's NIHR Biomedical Research Centres funding scheme. Merel Wassenaar and Bianca Berghuis were supported by the Christelijke Vereniging voor de Verpleging van Lijders aan Epilepsie (Nederland). Pauls Auce received funding from the University of Liverpool. Antonietta Coppola received research funding from the Italian League Against Epilepsy (LICE). Holger Lerche received support to recruit patients for pharmacogenomic studies from the German Society for Epileptology (DGfE) and the foundation no epilep. Josemir W. Sander's current 
position is endowed by the UK Epilepsy Society and he receives research support from the Dr. Marvin Weil Epilepsy Research Fund. Pasquale Striano received research support from the Italian Ministry of Health. Federico Zara received research support from the Italian Ministry of Health, the European Community Sixth, the Italian Ministry of Health, the Telethon Foundation and the Italian League Against Epilepsy.

\section{Disclosures}

Andreja Avbersek is employed by UCB Pharma SPRL Belgium as an Associate Director. Antonietta Coppola received research support, speaker's fees and travel grants from Eisai and travel grants from UCB Pharma. Gianpiero Cavalleri has received speaker's honoraria from UCB Pharma. Holger Lerche received support to recruit patients for pharmacogenomic studies from UCB Pharma. Josemir W. Sander has received departmental research support from GSK, Eisai and UCB Pharma and has been consulted by and received fees for lectures from Bial, Eisai and UCB Pharma. Graeme Sills has received honoraria from Eisai Ltd and UCB Pharma for speaking engagements unrelated to the submitted work. Pasquale Striano received honoraria from FB Health, Kolfarma s.r.l, UCB Pharma and Eisai Inc. Federico Zara received honoraria from Eisai Inc. M. Sanjay Sisodiya declares that he or his institution have received honororia or research support from UCB, Eisai, Vitaflo and Nutricia. Chantal Depondt has received research support and honoraria from UCB Pharma (for work not related to this manuscript and paid to the hospital). The remaining authors report no conflicts of interest.

We confirm that we have read the Journal's position on issues involved in ethical publication and affirm that this report is consistent with those guidelines. 


\section{References}

1. Panayiotopoulos CP. A Clinical Guide to Epileptic Syndromes and their Treatment. London: Springer London; 2010

2. Blümcke I, Spreafico R. Cause Matters: A Neuropathological Challenge to Human Epilepsies. Brain Pathol 2012; 22: 347-9.

3. Wieser HG, Häne A, Wieser HG, et al. Antiepileptic drug treatment in seizurefree mesial temporal lobe epilepsy patients with hippocampal sclerosis following selective amygdalohippocampectomy. Seizure 2004; 13: 534-6.

4. Wiebe S, Blume WT, Girvin JP, et al. A randomized, controlled trial of surgery for temporal-lobe epilepsy. N Engl J Med 2001; 345: 311-8.

5. Engel J, McDermott MP, Wiebe S, et al. Early surgical therapy for drugresistant temporal lobe epilepsy: a randomized trial. JAMA 2012; 307: 92230.

6. Labate A, Siniscalchi A, Mumoli L, et al. Topiramate and temporal lobe epilepsy: an open-label study. Epileptic Disord 2012; 14: 163-6.

7. Gomez-Ibañez A, Gasca-Salas C, Urrestarazu E, et al. Clinical phenotypes within non-surgical patients with mesial temporal lobe epilepsy caused by hippocampal sclerosis based on response to antiepileptic drugs. Seizure 2013; 22: $20-3$.

8. Palleria C, Coppola A, Citraro R, et al. Perspectives on treatment options for mesial temporal lobe epilepsy with hippocampal sclerosis. Expert Opin Pharmacother 2015; 16: 2355-71.

9. Arif $\mathrm{H}$, Buchsbaum R, Pierro J, et al. Comparative effectiveness of 10 antiepileptic drugs in older adults with epilepsy. Arch Neurol 2010; 67: 40815.

10. Zeng Q-Y, Fan T-T, Zhu P, et al. Comparative Long-Term Effectiveness of a 
Monotherapy with Five Antiepileptic Drugs for Focal Epilepsy in Adult Patients: A Prospective Cohort Study. PLoS One 2015; 10: e0131566.

11. Kwan P, Arzimanoglou A, Berg AT, et al. Definition of drug resistant epilepsy: Consensus proposal by the ad hoc Task Force of the ILAE Commission on Therapeutic Strategies. Epilepsia 2009; 51: 1069-77.

12. $\mathrm{R}$ Core Team. R: A language and environment for statistical computing. $\mathrm{R}$ Foundation for Statistical Computing, Vienna, Austria; 2014.

13. Lhatoo SD, Wong ICK, Polizzi G, et al. Long-Term Retention Rates of Lamotrigine, Gabapentin, and Topiramate in Chronic Epilepsy. Epilepsia 2000; 41: 1592-6.

14. Chung S, Wang N, Hank N, et al. Comparative retention rates and long-term tolerability of new antiepileptic drugs. Seizure 2007; 16: 296-304.

15. Peltola J, Peltola M, Auvinen A, et al. Retention rates of new antiepileptic drugs in localization-related epilepsy: a single-center study. Acta Neurol Scand 2009; 119: 55-60.

16. Hu Y, Huang Y, Quan F, et al. Comparison of the retention rates between carbamazepine and valproate as an initial monotherapy in Chinese patients with partial seizures: A ten-year follow-up, observational study. Seizure 2011; 20: 208-13.

17. Semah F, Lamy C, Demeret S. Hippocampal sclerosis and other hippocampal abnormalities in the early identification of candidates for epilepsy surgery. Arch Neurol 2002; 59: 1042-3; author reply 1043.

18. Stephen LJ, Kwan P, Brodie MJ. Does the cause of localisation-related epilepsy influence the response to antiepileptic drug treatment? Epilepsia 2001; 42: 357-62.

19. Varoglu AO, Saygi S, Acemoglu H, et al. Prognosis of patients with mesial 
temporal lobe epilepsy due to hippocampal sclerosis. Epilepsy Res 2009; 85: 206-11.

20. Sànchez J, Centanaro M, Solís J, et al. Factors predicting the outcome following medical treatment of mesial temporal epilepsy with hippocampal sclerosis. Seizure 2014; 23: 448-53.

21. " Kurita T, Sakurai K, Takeda Y, et al. Very Long-Term Outcome of NonSurgically Treated Patients with Temporal Lobe Epilepsy with Hippocampal Sclerosis: A Retrospective Study. PLoS One 2016; 11: e0159464.

22. Park KM, Shin KJ, Ha SY, et al. Response to antiepileptic drugs in partial epilepsy with structural lesions on MRI. Clin Neurol Neurosurg 2014; 123: 64-8.

23. Sillanpää M, Schmidt D. Natural history of treated childhood-onset epilepsy: prospective, long-term population-based study. Brain 2006; 129: 617-24.

24. Shorvon SD, Goodridge DMG. Longitudinal cohort studies of the prognosis of epilepsy: contribution of the National General Practice Study of Epilepsy and other studies. Brain 2013; 136: 3497-510.

25. Beghi E, Giussani G, Sander JW. The natural history and prognosis of epilepsy. Epileptic Disord 2015; 17: 243-53.

26. Neligan A, Bell GS, Elsayed M, et al. Treatment changes in a cohort of people with apparently drug-resistant epilepsy: an extended follow-up. J Neurol Neurosurg Psychiatry 2012; 83: 810-3.

27. Coan AC, Campos BM, Bergo FPG, et al. Patterns of seizure control in patients with mesial temporal lobe epilepsy with and without hippocampus sclerosis. Arq Neuropsiquiatr 2015; 73: 79-82.

28. Luciano AL, Shorvon SD. Results of treatment changes in patients with apparently drug-resistant chronic epilepsy. Ann Neurol 2007; 62: 375-81. 
29. Callaghan BC, Anand K, Hesdorffer D, et al. Likelihood of seizure remission in an adult population with refractory epilepsy. Ann Neurol 2007; 62: 382-9.

30. Carreño M, Maestro I, Molins A, et al. Pregabalin as add-on therapy for refractory partial seizures in every day clinical practice. Seizure 2007; 16: 709-12.

31. Perucca P, Gilliam FG. Adverse effects of antiepileptic drugs. Lancet Neurol 2012; 11: 792-802.

32. Deckers CL, Hekster YA, Keyser A, et al. Reappraisal of polytherapy in epilepsy: a critical review of drug load and adverse effects. Epilepsia 1997; 38:

\section{$570-5$}

33. Canevini MP, De Sarro G, Galimberti CA, et al. Relationship between adverse effects of antiepileptic drugs, number of coprescribed drugs, and drug load in a large cohort of consecutive patients with drug-refractory epilepsy. Epilepsia 2010; 51: 797-804.

34. Marson AG, Al-Kharusi AM, Alwaidh M, et al. The SANAD study of effectiveness of carbamazepine, gabapentin, lamotrigine, oxcarbazepine, or topiramate for treatment of partial epilepsy: an unblinded randomised controlled trial. Lancet (London, England) 2007; 369: 1000-15.

35. Andrade DM. Dravet syndrome, lamotrigine, and personalized medicine. Dev Med Child Neurol 2015; 57: 118-9.

36. Boerma RS, Braun KP, van den Broek MPH, et al. Remarkable Phenytoin Sensitivity in 4 Children with SCN8A-related Epilepsy: A Molecular Neuropharmacological Approach. Neurotherapeutics 2016; 13: 192-7.

37. Pierson TM, Yuan H, Marsh ED, et al. GRIN2A mutation and early-onset epileptic encephalopathy: personalized therapy with memantine. Ann Clin Transl Neurol 2014; 1: 190-8. 
38. Milligan CJ, Li M, Gazina E V., et al. KCNT1 gain of function in 2 epilepsy phenotypes is reversed by quinidine. Ann Neurol 2014; 75: 581-90.

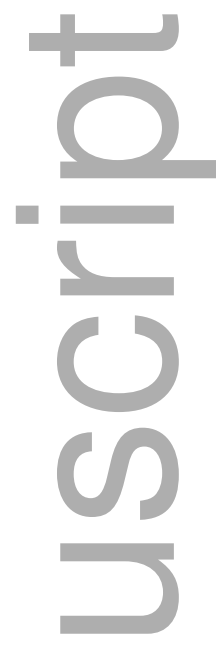

Figure 1. Flow chart for recruiting the patients with mesial temporal lobe epilepsy with hippocampal sclerosis.

Numbers of antiepileptic drug trials for drug retention, efficacy and adverse drug reactions include only those with interpretable data. Abbreviations: AED, antiepileptic drug.

Figure 2. Survival estimates for continuing AED treatments.

The bar plot shows the median survival estimate per AED. Their pairwise comparisons are given below as Bonferroni corrected p-values. Abbreviations: CBZ, carbamazepine; CLB, clobazam; GBP, gabapentin; LEV, levetiracetam; LTG, lamotrigine; ; OXC, oxcarbazepine; PGB, pregabalin; TPM, topiramate; VGB, vigabatrin; VPA, valproate. 


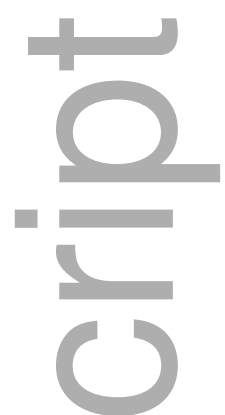

Table 1. Demographic and clinical details of the patient cohort.

\begin{tabular}{|c|c|c|}
\hline 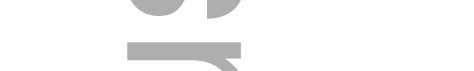 & Mean & Range \\
\hline \multicolumn{3}{|l|}{ Age (years) } \\
\hline At last visit & 45 & $15-77$ \\
\hline At epilepsy diagnosis & 16 & $1-74$ \\
\hline Epilepsy duration (years) & 30 & $1-71$ \\
\hline \multirow[t]{2}{*}{ AED trials per patient } & 4 & $1-12$ \\
\hline & Total Number & Percentage (\%) \\
\hline \multicolumn{3}{|l|}{ Sex } \\
\hline Male & 331 & 43.2 \\
\hline Female & 436 & 56.8 \\
\hline \multicolumn{3}{|l|}{ Ethnicity } \\
\hline European & 637 & 83.1 \\
\hline Other & 48 & 6.3 \\
\hline Unknown & 82 & 10.7 \\
\hline \multicolumn{3}{|l|}{ Sclerosis side } \\
\hline Left & 340 & 44.3 \\
\hline
\end{tabular}

This article is protected by copyright. All rights reserved 


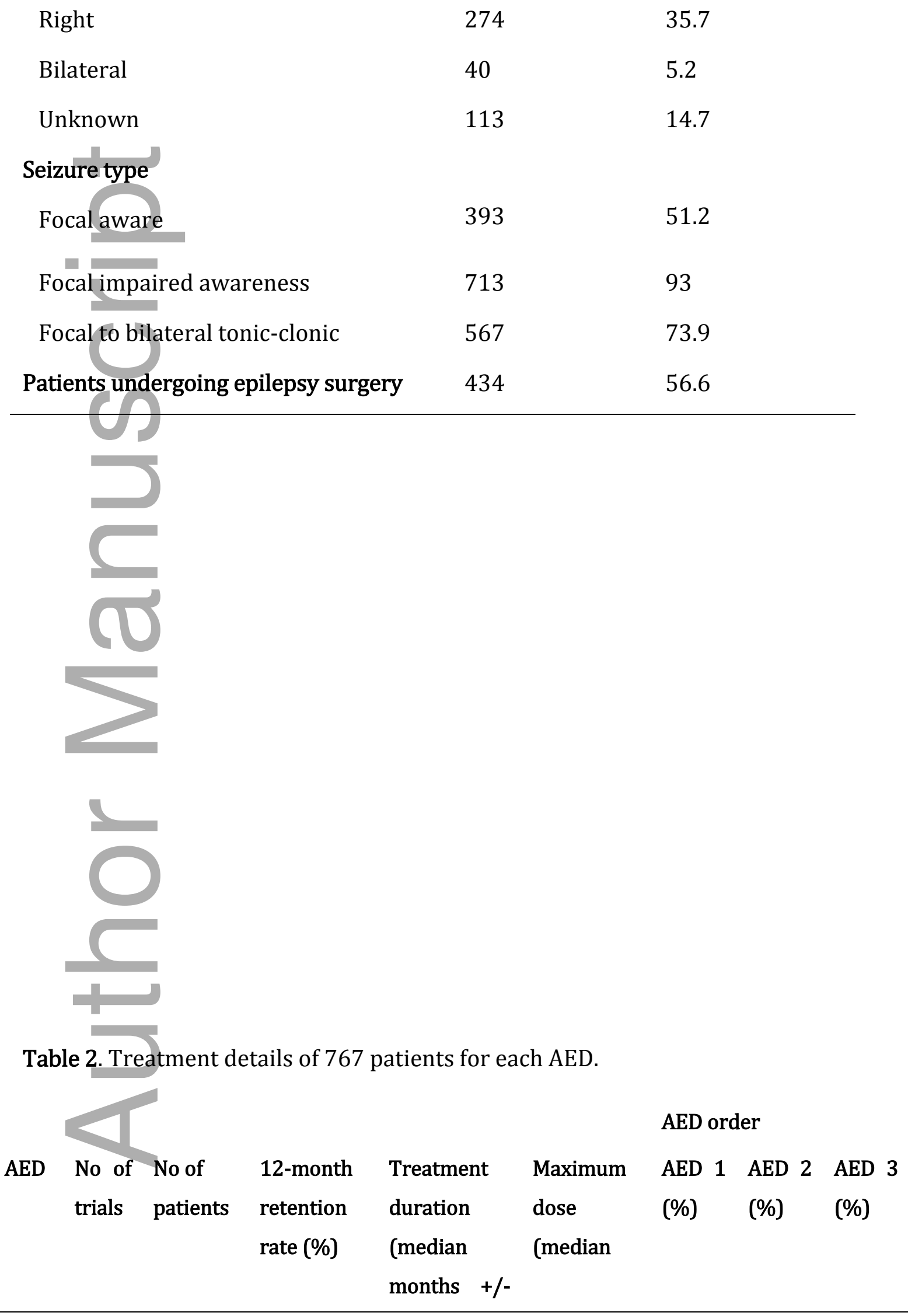

This article is protected by copyright. All rights reserved 


\begin{tabular}{lcccccccc}
\multicolumn{7}{c}{ MAD) } & mg/day) \\
\hline CBZ & 659 & 615 & 85.9 & $70+/-77.4$ & 1200 & 29.2 & 22.4 & 48.4 \\
VPA & 508 & 477 & 85.0 & $55+/-63.1$ & 1500 & 24.0 & 18.7 & 57.3 \\
LTG & 467 & 458 & 63.8 & $22+/-26$ & 400 & 9.9 & 14.5 & 75.6 \\
LEV & 431 & 423 & 71.3 & $31+/-37.2$ & 2875 & 4.6 & 8.4 & 86.9 \\
TPM & 308 & 304 & 63.8 & $17+/-17.4$ & 300 & 5.6 & 8.7 & 85.7 \\
CLB & 235 & 230 & 79.0 & $37+/-36.9$ & 20 & 7.1 & 12.0 & 80.9 \\
VGB & 233 & 231 & 69.4 & $26+/-27.7$ & 2500 & 3.7 & 13.0 & 83.3 \\
GBP & 194 & 192 & 64.3 & $14+/-15.3$ & 1800 & 8.1 & 9.4 & 82.5 \\
OXC & 141 & 140 & 51.4 & $12+/-15$ & 1500 & 6.9 & 11.1 & 82.0 \\
PGB & 73 & 73 & 40.0 & $10+/-9.8$ & 300 & 1.6 & 6.3 & 92.1 \\
\hline
\end{tabular}

Abbreviations: AED, antiepileptic drug; MAD, median absolute deviation; CBZ, carbamazepine; CLB, clobazam; GBP, gabapentin; LEV, levetiracetam; LTG, lamotrigine; OXC, oxcarbazepine; PGB, pregabalin; TPM, topiramate; VGB, vigabatrin; VPA, valproate. AED 1 means that the AED in question was the first AED used etc.

Table 3. AED outcome summary.

\begin{tabular}{llllll} 
AED & No of trials & Response (\%) & Failure (\%) & Unclassified & Unknown \\
\hline CBZ & 659 & $27(11)$ & $130(52.8)$ & 89 & 413 \\
VPA & 508 & $15(7.9)$ & $112(59.3)$ & 62 & 319 \\
LTG & 467 & $12(5.4)$ & $121(54.5)$ & 89 & 245 \\
LEV & 431 & $24(9.2)$ & $147(56.5)$ & 89 & 171 \\
TPM & 308 & $7(4.2)$ & $104(63)$ & 54 & 143 \\
CLB & 235 & $3(2.9)$ & $57(54.3)$ & 45 & 130 \\
VGB & 233 & $1(1.2)$ & $57(66.3)$ & 28 & 147 \\
GBP & 194 & $1(1.2)$ & $50(59.5)$ & 33 & 110
\end{tabular}




$\begin{array}{llllll}\text { OXC } & 141 & 7(8.2) & 61(71.8) & 17 & 56 \\ \text { PGB } & 73 & 2(4.7) & 18(41.9) & 23 & 30\end{array}$

Unclassified: the outcome is known but can be classified neither as a response nor a failure; unknown: the outcome is unknown, e.g. because insufficient information is available.

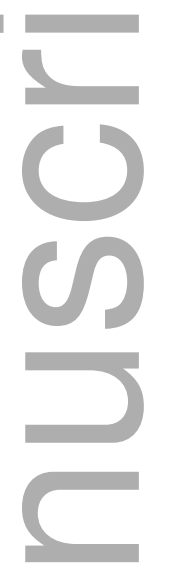

Table 4. Overall ADR incidence and top 10 most frequent ADRs per AED.

\begin{tabular}{llllllllllll}
\hline AED & $\begin{array}{l}\text { Patients } \\
\text { with ADR } \\
\text { (\%) }\end{array}$ & $\begin{array}{l}\text { Lethargy/d } \\
\text { rowsi-ness } \\
(\%)\end{array}$ & $\begin{array}{l}\text { Dizziness/ } \\
\text { Vertigo/At } \\
\text { axia (\%) }\end{array}$ & $\begin{array}{l}\text { Blurred } \\
\text { Vision/ } \\
\text { Diplopia } \\
(\%)\end{array}$ & $\begin{array}{l}\text { Behavio- } \\
\text { ral/emo- } \\
\text { tional } \\
\text { ADRs (\%) }\end{array}$ & $\begin{array}{l}\text { Weight } \\
\text { change } \\
(\%)\end{array}$ & $\begin{array}{l}\text { Cuta- } \\
\text { neous } \\
\text { ADRs } \\
(\%)\end{array}$ & $\begin{array}{l}\text { Cognitive } \\
\text { impair- } \\
\text { ment (\%) }\end{array}$ & $\begin{array}{l}\text { Tremor } \\
(\%)\end{array}$ & $\begin{array}{l}\text { Gastro- } \\
\text { intestinal } \\
\text { ADRs (\%) }\end{array}$ & $\begin{array}{l}\text { Depression } \\
(\%)\end{array}$ \\
\hline OXC & $50(35.7)$ & $9(6.4)$ & $13(9.2)$ & $15(10.6)$ & $4(2.8)$ & $0(0)$ & $6(4.3)$ & $3(2.1)$ & $2(1.4)$ & $2(1.4)$ & $1(0.7)$ \\
TPM & $94(30.9)$ & $17(5.5)$ & $10(3.2)$ & $0(0)$ & $20(6.5)$ & $18(5.8)$ & $2(0.6)$ & $32(10.4)$ & $0(0)$ & $7(2.3)$ & $13(4.2)$ \\
PGB & $20(27.4)$ & $4(5.5)$ & $4(5.5)$ & $0(0)$ & $1(1.4)$ & $4(5.5)$ & $0(0)$ & $0(0)$ & $0(0)$ & $2(2.7)$ & $1(1.4)$ \\
VPA & $100(21)$ & $13(2.6)$ & $3(0.6)$ & $0(0)$ & $3(0.6)$ & $28(5.5)$ & $4(0.8)$ & $4(0.8)$ & $35(6.9)$ & $14(2.8)$ & $2(0.4)$ \\
CBZ & $115(18.7)$ & $28(4.2)$ & $39(5.9)$ & $38(5.8)$ & $2(0.3)$ & $2(0.3)$ & $13(2)$ & $1(0.2)$ & $3(0.5)$ & $3(0.5)$ & $2(0.3)$ \\
LEV & $74(17.5)$ & $31(7.2)$ & $12(2.8)$ & $0(0)$ & $29(6.7)$ & $0(0)$ & $1(0.2)$ & $2(0.5)$ & $3(0.7)$ & $6(1.4)$ & $16(3.7)$ \\
VGB & $39(16.9)$ & $3(1.3)$ & $0(0)$ & $5(2.1)$ & $0(0)$ & $5(2.1)$ & $0(0)$ & $1(0.4)$ & $1(0.4)$ & $0(0)$ & $4(1.7)$ \\
LTG & $76(16.6)$ & $17(3.6)$ & $23(4.9)$ & $14(3)$ & $2(0.4)$ & $0(0)$ & $31(6.6)$ & $2(0.4)$ & $0(0)$ & $5(1.1)$ & $1(0.2)$ \\
GBP & $17(8.9)$ & $7(3.6)$ & $1(0.5)$ & $0(0)$ & $1(0.5)$ & $3(1.5)$ & $0(0)$ & $2(1)$ & $0(0)$ & $5(2.6)$ & $2(1)$ \\
CLB & $15(6.5)$ & $6(2.6)$ & $0(0)$ & $0(0)$ & $3(1.3)$ & $1(0.4)$ & $2(0.9)$ & $1(0.4)$ & $1(0.4)$ & $0(0)$ & $1(0.4)$ \\
\hline
\end{tabular}




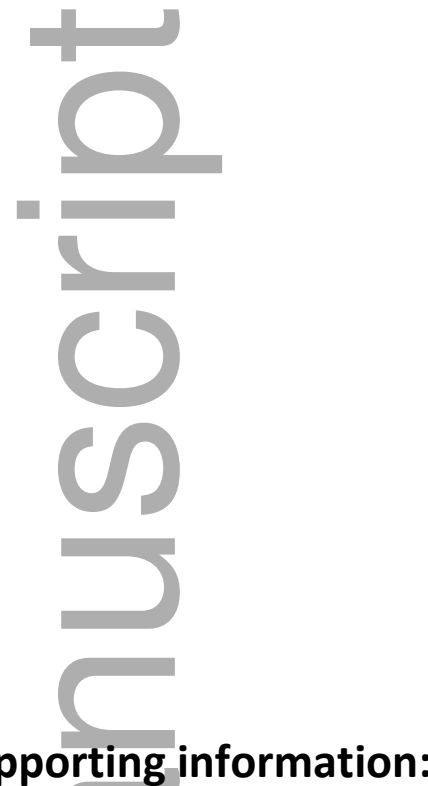

\section{Supporting information:}

Supplementary Table 1 . Breakdown of subjects by centres

Supplementary Figure 1. Distribution of AED start dates

Supplementary Figure 2. AED treatment duration

Supplementary Table 2. Order of AED use

Supplementary Figure 3. Frequencies of patients' age distribution

Supplementary Table 3. Reasons for AED discontinuation

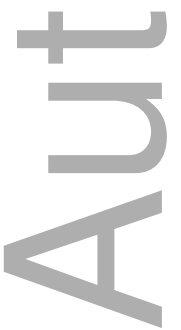




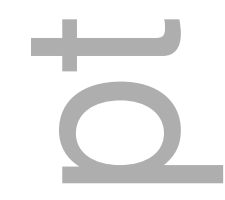

$\square$
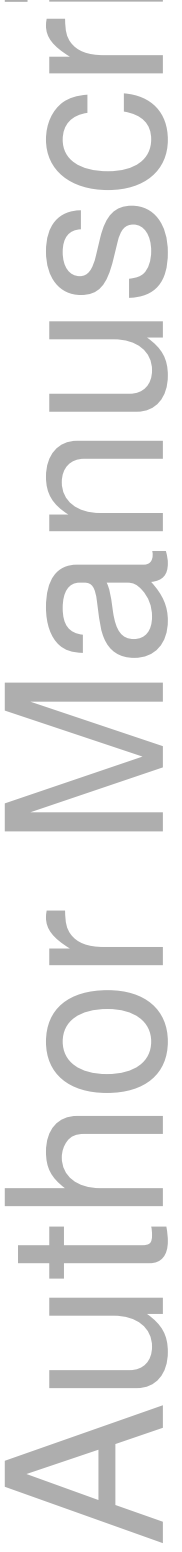

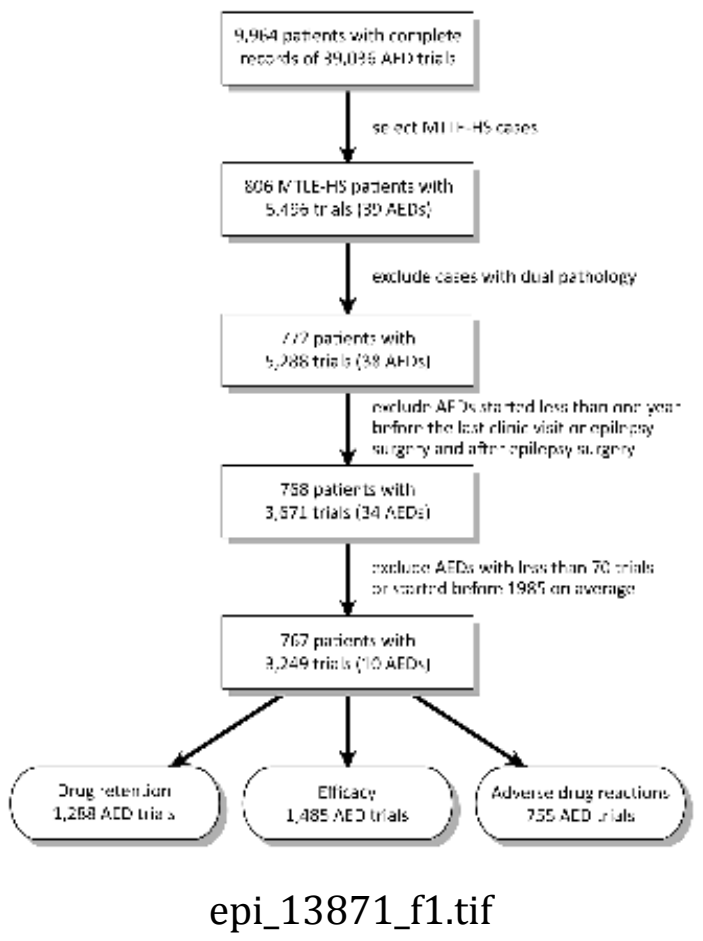

epi_13871_f1.tif 


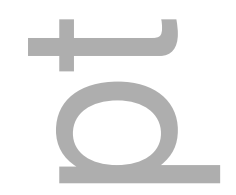

D
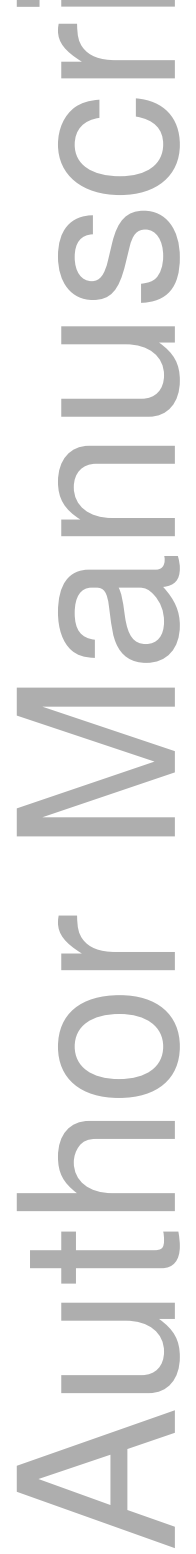

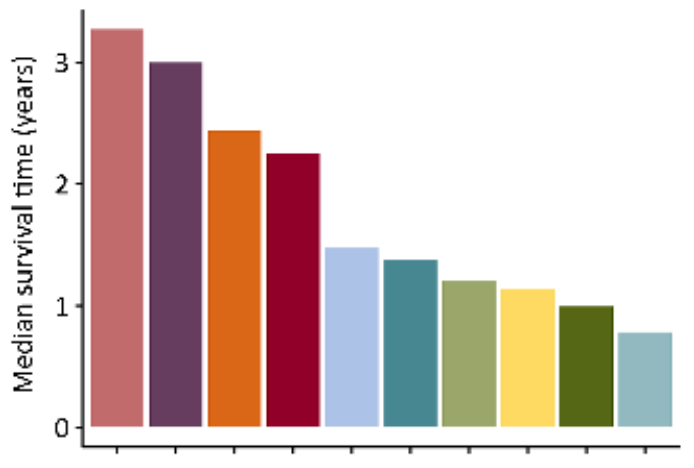

CBZ VPA LEV CLB VGB TPM LTG GBP OXC PGB

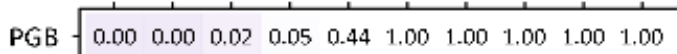

$$
\begin{aligned}
& \begin{array}{llllllllll}
\text { OXC }-0.00 & 0.00 & 0.00 & 0.00 & 0.05 & 0.30 & 0.31 & 1.00 & 1.00
\end{array} \\
& \text { GBP }-\begin{array}{llllllll}
0.00 & 0.00 & 0.00 & 0.02 & 0.42 & 1.00 & 1.00 & 1.00
\end{array} \\
& \begin{array}{lllllllll}
\text { LTG }-0.00 & 0.12 & 0.07 & 0.74 & 1.00 & 1.00 & 1.00
\end{array} \\
& \text { TPM }-0.00 \quad 0.04 \quad 0.05 \quad 0.71 \quad 1.00 \quad 1.00 \\
& \text { VGB }-\begin{array}{llllll}
0.30 & 1.00 & 1.00 & 1.00 & 1.00
\end{array} \\
& \begin{array}{llllll}
\text { CLB } & -1.00 & 1.00 & 1.00 & 1.00
\end{array} \\
& \text { LEV }-1.00 \quad 1.00 \quad 1.00 \\
& V P A-1.00 \quad 1.00 \\
& \mathrm{CBZ} \uparrow 1.00
\end{aligned}
$$

epi_13871_f2.tif 


\section{University Library}

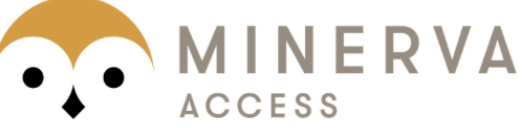

A gateway to Melbourne's research publications

Minerva Access is the Institutional Repository of The University of Melbourne

\section{Author/s:}

Androsova, G;Krause, R;Borghei, M;Wassenaar, M;Auce, P;Avbersek, A;Becker,

F;Berghuis, B;Campbell, E;Coppola, A;Francis, B;Wolking, S;Cavalleri, GL;Craig, J;Delanty, N;Koeleman, BPC;Kunz, WS;Lerche, H;Marson, AG;Sander, JW;Sills, GJ;Striano, P;Zara, F;Sisodiya, SM;Depondt, C

Title:

Comparative effectiveness of antiepileptic drugs in patients with mesial temporal lobe epilepsy with hippocampal sclerosis

Date:

2017-10-01

\section{Citation:}

Androsova, G., Krause, R., Borghei, M., Wassenaar, M., Auce, P., Avbersek, A., Becker, F., Berghuis, B., Campbell, E., Coppola, A., Francis, B., Wolking, S., Cavalleri, G. L., Craig, J., Delanty, N., Koeleman, B. P. C., Kunz, W. S., Lerche, H., Marson, A. G. ,... Depondt, C. (2017). Comparative effectiveness of antiepileptic drugs in patients with mesial temporal lobe epilepsy with hippocampal sclerosis. EPILEPSIA, 58 (10), pp.1734-1741. https:// doi.org/10.1111/epi.13871.

Persistent Link:

http://hdl.handle.net/11343/293389 